\title{
A indústria fonográfica e o mercado da música gravada - histórias de um longo desentendimento
}

The Phonographic Industry and the Recorded Music Market - A Long

Misunderstanding

L'industrie phonographique et le marché de la musique enregistrée - histoires

d'une longue mésentente

\section{Paula Abreu}

\section{(2) OpenEdition}

\section{Journals}

Edição electrónica

URL: http://journals.openedition.org/rccs/356

DOI: $10.4000 /$ rccs.356

ISSN: 2182-7435

\section{Editora}

Centro de Estudos Sociais da Universidade de Coimbra

\section{Edição impressa}

Data de publição: 1 Junho 2009

Paginação: 105-129

ISSN: 0254-1106

\section{Refêrencia eletrónica}

Paula Abreu, «A indústria fonográfica e o mercado da música gravada - histórias de um longo desentendimento », Revista Crítica de Ciências Sociais [Online], 85 | 2009, colocado online no dia 01 dezembro 2012, criado a 19 abril 2019. URL : http://journals.openedition.org/rccs/356 ; DOI : $10.4000 /$ rccs.356

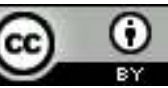




\section{PAULA ABREU}

\section{A indústria fonográfica e o mercado da música gravada - histórias de um longo desentendimento*}

Com base numa pesquisa sobre a indústria fonográfica portuguesa, o artigo aborda a situação de crise que esta indústria actualmente atravessa com o objectivo de mostrar como a história do campo fonográfico foi, desde o início, marcada por dúvidas e incertezas várias, decorrentes de disputas sobre múltiplos objectos, e de como essas dúvidas sempre conduziram à reinvenção das convenções que têm plasmado a actividade deste campo organizacional e mercantil.

A partir de uma perspectiva analítica que mobiliza contributos das correntes teóricas da sociologia económica de inspiração institucionalista (Powell e DiMaggio, 1991; Fligstein, 1996 e 2001) e da economia das convenções (Boltanski e Thévenot, 1991 e 1999; Thévenot, 2002), propõe-se uma discussão acerca dos dilemas vividos por esta indústria, explorando a hipótese de os mesmos decorrerem da diversidade de ordens de grandeza mobilizadas na coordenação das actividades do campo fonográfico.

Palavras-chave: indústria fonográfica, história; incerteza; coordenação; ordens de grandeza.

$\mathrm{Na}$ literatura sobre as indústrias culturais e, em particular, sobre a indústria fonográfica, são escassos os trabalhos que interrogam consistentemente os processos de instituição destes universos de actividade como campos industriais e como campos mercantis. De facto, na sociologia, tal como na economia, é frequente ver mobilizados para a análise e a descrição deste tipo de objectos conceitos tão abstractos como os de modo de produção industrial capitalista e de mercado. Porém, a sua fecundidade analítica depende, em grande medida, de uma operacionalização crítica, capaz de identificar as dimensões mais pertinentes para cada objecto. No caso da indústria e do mercado fonográficos, tal operacionalização exige uma interrogação acerca da forma como estas actividades se foram desenvolvendo

* Uma versão mais curta deste texto foi apresentada no congresso internacional Sociologia da Música: Tendências, Interpelações, Perspectivas, organizado pelo CESEM e realizado em Lisboa entre 23 e 25 de Julho de 2009. 
historicamente de modo a instituir um universo que é simultaneamente industrial, mercantil e cultural.

Perceber as condições em que, no final do século XIX e no início do século $\mathrm{Xx}$, surgiram um novo conjunto de actividades, de equipamentos e de objectos, e compreender os processos através dos quais se foram constituindo os respectivos valores de uso e de troca, parece-me uma estratégia adequada para evitar a reprodução de visões mais ou menos simplistas sobre um complexo universo.

Para desenvolver este enfoque analítico inspiro-me nas perspectivas institucionalistas da economia e da sociologia, nomeadamente as teses de Paul DiMaggio e de Walter Powell acerca dos campos organizacionais e de Neil Fligstein acerca dos mercados (Powell e DiMaggio, 1991; Fligstein, 1996; Fligstein, 2001). O enfoque analítico destas teorias relativiza o contributo das racionalidades técnica e mercantil no desenvolvimento das actividades económicas, mostrando como elas se combinam com um conjunto de outras racionalidades de carácter convencional, que subjazem à institucionalização dos campos organizacionais e seus mercados. Para identificar esta articulação de lógicas e de racionalidades diversas é indispensável recorrer a uma análise histórica sobre a constituição desses mesmos campos. Foi essa perspectiva analítica que procurei desenvolver ao estudar a indústria fonográfica, com o objectivo de captar os processos de formação dos padrões institucionais que têm vindo a enformar a actividade desta indústria, a organização das suas companhias e o funcionamento dos mercados. A adopção desta perspectiva possibilita, ainda, o diálogo com a teoria dos campos de Pierre Bourdieu, aplicando a uma indústria cultural a perspectiva estruturalista e genética adoptada pelo autor para descrever os campos culturais (Bourdieu, 1996).

Uma abordagem histórica sobre a indústria fonográfica permite revelar, em primeiro lugar, a pluralidade dos objectos que têm sido alvo de lutas e de negociações entre os vários intervenientes no campo. E em segundo lugar, evidencia a natureza distinta desses objectos, que não se restringem apenas às ordens do económico ou do cultural, como propõe Pierre Bourdieu. Nesse sentido, a história mostra como a afirmação das actividades fonográficas enquanto campo industrial e cultural decorre da luta por recursos de natureza diversa e pela negociação de variadas convenções. Partilhadas pelos diferentes actores no campo (companhias fonográficas, sindicatos profissionais, associações de gestão de direitos de propriedade, associações de companhias...), são essas convenções que permitem a coordenação das suas acções no sentido da produção, da difusão e do consumo dos seus produtos. Não obstante, os processos de definição dessas convenções foram 
sempre complexos e morosos, reflectindo a mobilização de diversos regimes de acordo e modos de justificação ou, na expressão de Luc Boltanski e Laurent Thévenot, diferentes ordens de grandeza. Segundo estes autores, existem pelo menos seis regimes - o da inspiração, o doméstico, o da reputação, o cívico, o industrial e o de mercado -, cada um deles envolvendo a articulação entre um princípio de grandeza relevante para a acção, os testes ou provas dessa mesma grandeza e as correspondentes ordenações ou hierarquias; os actores sociais pertinentes, para além dos objectos e dos dispositivos materiais e técnicos que materializam cada uma dessas ordens (Boltanski e Thévenot, 1991 e 1999; Thévenot, 2001 e 2002). Reflectindo a articulação com diferentes regimes de acordo e justificação, a constituição das convenções do campo da indústria fonográfica revela disputas e acordos que não se restringem às questões técnicas ou mercantis, associadas às ordens industrial e do mercado. São também observáveis lutas e negociações acerca de conteúdos e de formatos culturais, devedoras dos princípios da ordem da inspiração; ou contendas sobre modelos de apresentação e difusão pública de companhias, de fonogramas e de artistas, orientadas pelas lógicas inerentes à ordem da reputação; ou ainda controvérsias sobre as definições de propriedade e as formas de regulação pública dos respectivos direitos, evocativas dos princípios da ordem cívica.

O objectivo principal deste texto é exactamente o de mostrar como a história da indústria fonográfica e dos seus mercados foi, desde o seu início, marcada por dúvidas e incertezas várias, decorrentes de disputas sobre diferentes objectos, e de como essas dúvidas sempre conduziram à reinvenção das convenções que têm vindo a plasmar a actividade deste campo organizacional e mercantil. Na parte final do texto, procurarei ainda descrever a actual crise da indústria fonográfica como mais uma situação de incerteza crítica, em que os actores implicados se debatem com interrogações capitais acerca do que define o valor comum dos fonogramas e de como esse valor pode continuar a coordenar uma cadeia de actividades que vai da criação ao uso e fruição da música gravada.

\section{Das incertezas primordiais às primeiras convenções}

$\mathrm{Na}$ abundante literatura acerca da história do registo sonoro é frequente encontrar a identificação de Thomas Edison e da sua invenção do fonógrafo (phonogragh) como a personagem e o acontecimento primordiais da indústria fonográfica. O fonógrafo, um aparelho inventado nos laboratórios de Edison em 1877, foi, de facto, o primeiro aparelho de registo sonoro formalmente reconhecido através de um registo de patente, em 1878. No entanto, procurar definir um acontecimento ou uma personagem fundado- 
res é uma estratégia equívoca quando se trata de compreender o desenvolvimento do campo fonográfico. Adoptar a sugestão de Andre Millard, que situa os primórdios do que hoje conhecemos como indústria fonográfica no contexto da revolução das comunicações é, em alternativa, uma estratégia mais produtiva (Millard, 2005: 17). A adopção desse pressuposto permite avaliar o modo como, a partir de um contexto relativamente indiferenciado de inovações tecnológicas e de aplicações industriais, se foi definindo o processo que conduziu à formação de um universo específico de actividades industriais e culturais.

De facto, a revolução das comunicações teve início em meados do século XIX, com a invenção e o desenvolvimento do telégrafo. Na sequência da aplicação desta tecnologia, multiplicaram-se o número e a velocidade das comunicações, e o registo e a reprodução do som tornaram-se o objecto de novas pesquisas. Em 1876, Alexandre Bell registou a patente do telefone e, logo no ano seguinte, Thomas Edison anunciava a invenção do fonógrafo. Todavia, Bell e Edison são duas personagens entre muitas outras que exploraram e ensaiaram as novas técnicas e tecnologias, nos domínios do som, da electricidade e da comunicação. ${ }^{1}$ As ideias que Edison aplicou no desenvolvimento do fonógrafo foram exploradas por muitos outros inventores que, à época, conheciam as técnicas associadas à electricidade e ao som, nomeadamente as suas aplicações no telégrafo e no telefone - é o caso de Charles Tainter e Chichester Bell, que desenvolveram o grafofone, ${ }^{2}$ e também de Émile Berliner, o inventor do gramofone.

O enquadramento destas invenções no âmbito da fervilhante actividade de invenção e inovação tecnológica do século XIX e do intenso desenvolvimento industrial que a Inglaterra e os Estados Unidos, sobretudo, conheciam à época, permite dar conta do carácter arbitrário da atribuição das origens da indústria fonográfica ao aparecimento dos primeiros equipamentos de registo sonoro. Desde logo, porque existe uma descoincidência razoável entre os usos atribuídos pelos inventores aos novos aparelhos e aqueles que foram sendo reinventados na relação entre condicionantes

\footnotetext{
${ }^{1}$ Tal como Millard, também Oliver Read e Walter L. Welch consideram que a história do moderno fonógrafo começou, de facto, com a invenção do telégrafo e com as pesquisas em torno da comunicação telegráfica e telefónica. De tal modo que os principais nomes da invenção das primeiras "máquinas falantes" (Edison, Bell e Berliner) haviam estado todos envolvidos na pesquisa sobre a comunicação por telégrafo e telefone (Read e Welch, 1976: 1-10).

${ }^{2}$ O grafofone foi desenvolvido por Tainter e Bell nos laboratórios Volta, de Alexandre Bell, com base na tecnologia do fonógrafo de Edison, introduzindo melhorias técnicas e tecnológicas sobre o tipo de cilindro usado no registo sonoro. A. Bell propôs a Edison a sua exploração conjunta mas este recusou, retomando o trabalho sobre o fonógrafo e aperfeiçoando-o a partir das experiências de Tainter e C. Bell com o grafofone (Millard, 2005: 17-36).
} 
técnicas e tecnológicas e o universo dos seus utilizadores: inventores, divulgadores, comerciantes e públicos.

Edison é, no que a isto diz respeito, um exemplo paradigmático de desacerto. De facto, como mostra Sophie Maisonneuve, o célebre inventor definiu um amplo script para o fonógrafo, situando-o num contexto similar ao de outras invenções associadas à comunicação. Isto é, como um aparelho destinado a conservar e a reproduzir o som e, por isso, aplicável a diversas actividades administrativas, arquivísticas e pedagógicas. Um prolongamento do telefone, cujas aplicações seriam particularmente úteis no domínio das práticas administrativas (Maisonneuve, 2002: 49). Embora esse script fosse suficientemente aberto para acolher as reconfigurações que a apropriação do fonógrafo vieram a inscrever, o mesmo não deixa de revelar a enorme distância entre as concepções do inventor sobre o aparelho e as suas futuras utilizações.

As limitações tecnológicas e técnicas relativas à própria gravação sonora obstaram a que o fonógrafo se tornasse, de imediato, num dispositivo de comunicação, no sentido em que Edison o imaginou. Entretanto, a divulgação dos aparelhos em exposições, feiras industriais e em exibições nos laboratórios, nas ruas e nos estabelecimentos comerciais revelou o potencial dos equipamentos para o entretenimento - para além da curiosidade nas invenções e nos seus potenciais usos, o público revelava gostar sobretudo do que som que se fazia ouvir. O sucesso destas exibições redefiniu os usos esperados da "máquina falante" e, com isso, colocou novos problemas relativos à manipulação do equipamento, à possibilidade da reprodução sonora (sem desgaste do suporte e do som registado), à produção de registos sonoros dedicados à audição lúdica, bem como a respectiva produção em quantidade.

Estes problemas foram colocados aos inventores dos equipamentos de registo fonográfico à medida que se foram ensaiando os seus usos em público e explicam o lapso de tempo que decorre entre a invenção do fonógrafo e a produção industrial e comercialização quer dos equipamentos, quer dos registos sonoros necessários à sua performance. De facto, só nos primeiros anos do século Xx é que foram ultrapassadas as principais dificuldades da produção industrial destes frágeis equipamentos, encontrando-se em actividade, nos Estados Unidos da América, as três principais companhias responsáveis pela sua produção: a companhia fundada por Thomas Edison - The Edison Phonograph Company -, a Victor Talking Machine, de Eldridge Johnson e Émile Berliner, e a Columbia Phonograph Company, um agente da então já desaparecida North American Phonograph Company, criada por Joseph Lippincott para produzir os primeiros modelos do fonógrafo de 
Edison. Como refere Millard, “As companhias Edison, Victor e Columbia eram como conhecidas como As Três Grandes. Dominavam o mercado com um forte controle sobre patentes e com vastas instalações industriais. Após muitos anos de falhanços repetidos e de duras lições, estas companhias tinham finalmente conseguido aplicar o sistema americano de produção industrial à máquina falante" (Millard, 2005: 50).

Apesar dos equívocos associados às primeiras antevisões dos usos das 'máquinas falantes', Pekka Gronow e Ilpo Saunio (1999: 1-7) assinalam o facto de, no início do século xx, Edison já ter percebido que o fonógrafo era sobretudo uma "caixa de música", dedicando-se então à produção de cilindros gravados e lançando um novo modelo de fonógrafo destinado a equipar os lares americanos (the home phonograph, como lhe chamou). Entretanto, também o gramofone, de Berliner, havia conhecido aperfeiçoamentos substanciais, sobretudo com os contributos de Eldridge Johnson. Foi Johnson quem concebeu o motor que foi acoplado ao gramofone, permitindo o seu funcionamento autónomo. E foi também ele quem concebeu o processo de gravação de matrizes em discos de cera, melhorando a qualidade das gravações e permitindo a reprodução em massa dos discos gravados.

Assim, e apesar de subsistirem ainda muitas limitações técnicas e tecnológicas relativas quer aos aparelhos (fonógrafo e gramofone), quer aos suportes (cilindros e discos), quer às próprias técnicas de registo de som (ainda acústicas), nos primeiros anos do século Xx existiam já condições técnicas para o desenvolvimento da actividade industrial fonográfica.

Não obstante, faltavam ainda várias outras condições para a constituição de verdadeiros mercados. A primeira é a que diz respeito ao encontro dessa oferta com uma potencial procura, sustentada em hábitos e práticas sociais de integração e uso dos novos objectos - os aparelhos e os registos sonoros. De facto, como sugere Sophie Maisonneuve, a história do fonógrafo/gramofone e da indústria fonográfica tem-se centrado sobre os aspectos tecnológicos, industriais e económicos, negligenciando os seus usos e os seus utilizadores (Maisonneuve, 2001b: 91). É, contudo, o processo de transformação dos novos equipamentos em novos media musicais e a constituição de uma nova cultura musical que permitem consolidar a actividade da indústria e do mercado fonográfico a partir dos anos 20.

Nas primeiras duas décadas do século passado, conjugaram-se condições económicas e tecnológicas que permitiram baixar o preço dos equipamentos e dos registos sonoros e alargar o volume e a diversidade do repertório musical gravado. A principal inovação tecnológica diz respeito à introdução do microfone, que permitiu não só melhorar significativamente a qualidade sonora dos registos, como gravar a performance de 
formações musicais mais amplas, um leque mais vasto de instrumentos e, por isso mesmo, uma maior diversidade de repertório. Em simultâneo, os avanços na tecnologia do suporte, nomeadamente a introdução do disco de dupla face e o alargamento do tempo de gravação sonora em cada um dos lados do disco, multiplicaram os efeitos da gravação com microfone, permitindo um crescimento substancial do número de registos sonoros comercializados. Por seu turno, a evolução dos gramofones como equipamentos portáteis multiplicou as possibilidades de audição de discos. Este conjunto de inovações explica, em grande medida, o facto de o gramofone se afirmar como o aparelho de reprodução sonora por excelência, o medium musical de que fala Maisonneuve (2001a), suplantando definitivamente o fonógrafo.

Estas novas condições tecnológicas reflectiram-se no modo como os consumidores foram desenvolvendo um conjunto de novos usos materiais e estéticos da música, dos equipamentos e dos discos. O trabalho de Sophie Maisonneuve mostra como a audição doméstica de discos envolve, simultaneamente, uma nova forma de consumo de música e um novo modo de audição musical. ${ }^{3}$ Um consumo que tem lugar no espaço doméstico e envolve cuidadosas operações de manipulação do gramofone e dos discos, dando lugar à formação de competências e a disposições específicas. Um consumo que materializa a música, retira aos discos o estatuto de objectos de luxo e os transforma em mercadorias passíveis de colecção. Em suma, um consumo que altera os modos de relação com a música, pois permite a escuta repetida das obras, a comparação de registos, a acumulação de conhecimentos estético-musicais e experiências emocionais, estimulando uma forma de audição cuja variável central é o som. Uma "escuta aural" que tem lugar no espaço privado da casa e é favorável à construção de universos íntimos de fruição estética (Maisonneuve, 2001a).

A formação desta nova cultura musical e a instituição do gramofone como medium musical por excelência têm um significado cultural particular, no contexto da formação da nova indústria. De facto, estes processos envolveram particularmente a forma de expressão musical que, à época, assumia o mais significativo valor estético e social - a música 'clássica', o repertório

\footnotetext{
${ }^{3}$ A autora mostra de forma viva o modo como, em França e em Inglaterra, os amantes de música foram desenvolvendo competências técnicas e operacionais que estimularam a constituição de novas disposições estéticas de audição musical. Para isso recorre aos depoimentos que surgem em inúmeras publicações que, no início do século Xx, circulavam na Inglaterra e em França. Simultaneamente, a autora evidencia o modo como os críticos musicais contribuíram para o mesmo processo, assumindo funções pedagógicas, e as companhias se adaptaram editando manuais para os equipamentos e catálogos de apresentação e descrição dos registos editados. Para uma apresentação analítica destes processos, ver Maisonneuve, 2002.
} 
musical que, ao longo dos séculos XVIII e XIX, se tinha vindo a constituir como o cânone musical por excelência (DeNora, 1995; Weber, 1989). A sua assimilação como parte do repertório musical gravado contribuiu grandemente para o reconhecimento cultural da indústria fonográfica, quer na Europa, quer nos Estados Unidos da América. ${ }^{4}$ Mas, como referem Maisonneuve (2002) e Chanan (1995), a transformação do gramofone em novo medium musical envolve igualmente um conjunto de expressões musicais populares que haviam explodido a partir de meados do século XIX, com o desenvolvimento de novas formas de lazer. Através dos discos, estas expressões musicais populares conquistaram o espaço público e associaram-se a novas formas de sociabilidade e lazer.

Para além da formação dessa nova cultura musical, essencial para o desenvolvimento das procuras necessárias à constituição dos mercados fonográficos, outras condições limitavam a formação de campos industriais polarizados em torno de mercados de bens fonográficos. Uma dessas limitações estava associada à natureza dos bens produzidos pela própria indústria. Como refere Simon Frith (1988: 11-23), no final do século XIX e no início do século Xx, a indústria fonográfica era sobretudo uma indústria de hardware, mais do que de software, integrando a actividade da indústria eléctrica. No entanto, como sugere Michael Chanan (1995: 23-36), a particularidade desta indústria residia na existência de uma associação técnica que fazia com que as suas mercadorias assumissem uma dupla forma: a de equipamento de registo/reprodução sonora - o fonógrafo ou o gramofone; e a do registo fonográfico - o cilindro ou o disco. E mais ainda: os sons produzidos por esses objectos não existiriam senão na necessária co-presença de equipamentos, de suportes e registos sonoros. Em consequência, os produtores de equipamentos de registo e reprodução sonoros tiveram necessariamente de acrescentar à sua actividade a produção dos conteúdos: "Na medida em que não se pode ter um sem o outro, tal deu origem a um princípio geral segundo o qual os produtores de qualquer tipo de hardware

\footnotetext{
4 Também do ponto de vista da produção dos registos fonográficos, daquilo que David Morton designa como recording culture (Morton, 2000: 13-47), e apesar de a música popular constituir a maior fonte de crescimento da indústria fonográfica ao longo da sua história, a música clássica foi a forma musical que, nos anos da formação da indústria, mais influenciou as mudanças tecnológicas e as práticas dos estúdios de gravação: "Os executivos das companhias de gravação por vezes revelaram que os seus catálogos de registos clássicos tinham como principal objectivo o prestígio, não o dinheiro. A influência da música erudita no desenvolvimento da tecnologia de gravação excedeu amplamente a importância económica das respectivas vendas de discos ou a dimensão das audiências de tal música. De facto, a alta-fidelidade e a alta cultura desempenharam papéis importantíssimos no estabelecimento das bases da engenharia do registo sonoro e ainda hoje continuam a exercer influência” (Morton, 2000:16-17).
} 
têm eles próprios de se preocupar com a produção de software adequado, sem o qual o hardware não tem mercado" (Chanan, 1995: 32).

Nos primeiros tempos em que as companhias fonográficas perceberam o carácter vital da produção de registos sonoros para o sucesso da produção de equipamentos, vários foram os obstáculos que tiveram, ainda, de ultrapassar. Nesse contexto, e como referi anteriormente, o sistema criado por Berliner e posteriormente aperfeiçoado e desenvolvido por Eldridge Johnson, revelou-se o mais ágil na resposta às necessidades de replicação dos registos sonoros. Os discos, ao contrário do que acontecia com os cilindros, podiam já ser reproduzidos a partir de uma matriz e, portanto, produzidos em quantidades aceitáveis para a procura de um mercado (Millard, 2005: 48-49). Berliner e Johnson asseguraram ainda outra vantagem, pois foram igualmente pioneiros no envio, para a Europa, de técnicos especialistas na gravação sonora, com o intento de dilatar o leque de gravações musicais à disposição das suas companhias. Os mais conhecidos desses técnicos são os célebres irmãos Gaisberg, responsáveis por inúmeras gravações que constam nos primeiros catálogos da Gramophone Company (em Inglaterra) e da Victor Talking Machine (nos Estados Unidos), realizadas na Europa e um pouco por todo o mundo. A sensibilidade musical de Fred Gaisberg permitiu às duas companhias um estratégico desenvolvimento dos seus catálogos de discos, recheado de registos das mais importantes obras e intérpretes da música clássica, mas também de gravações de intérpretes e de temas musicais populares, dos mais diversos pontos do mundo.

Edison teve mais dificuldades em se convencer da necessidade de multiplicação dos registos sonoros, sendo mais sensível aos aperfeiçoamentos técnicos e tecnológicos do fonógrafo, dos seus cilindros e da qualidade do som reproduzido. A sua visão relativamente ao universo da produção e do registo musical foi mais conservadora, centrando-se sobre os dispositivos materiais e desvalorizando o facto de o valor técnico e mercantil destes estar intimamente associado ao conteúdo especificamente musical dos sons gravados. Mais tarde, este equívoco de Edison viria a ser um factor determinante para a debilidade da sua companhia fonográfica e mesmo para o seu desaparecimento, em 1928.

A importância do conteúdo cultural das actividades fonográficas tornara-se de tal forma evidente que os próprios compositores e autores, e os respectivos editores gráficos, reivindicaram a extensão das regras do direito de autor ao universo da 'música mecânica'. Essa disputa foi dirimida pelos Estados, primeiramente através dos tribunais e, depois, através da consagração legal dos direitos de propriedade dos autores e composi- 
tores sobre as obras que eram objecto de gravação fonográfica nas legislações nacionais e em acordos internacionais - nomeadamente na Convenção de Berna, assinada em Paris, em 1890, e revista em Berlim em 1908 (Chanan, 1995: 23-36). ${ }^{5}$

A apresentação, ainda que breve, de alguns dos aspectos da história do campo fonográfico nas suas primeiras décadas de vida, isto é, nos tempos da sua institucionalização organizacional, teve como objectivo colocar em evidência as múltiplas ambiguidades que pautaram esses momentos primordiais e cuja solução impôs a negociação de acordos relativamente aos regimes de justificação a adoptar. Essas ambiguidades surgiram no contexto de actividades orientadas por duas ordens de grandeza dominantes: a ordem industrial subjacente à actividade inventiva que marcou o século XIX e que produziu um conjunto amplo de novos artefactos técnicos, nomeadamente o fonógrafo; a ordem mercantil, associada à produção para o mercado desses mesmos artefactos. O surgimento de um novo artefacto como o fonógrafo e a sua orientação para o mercado exigiu uma negociação sobre os usos relevantes desse mesmo objecto. Uma negociação complexa dado que não envolveu apenas os especialistas técnicos da concepção e produção e os profissionais do mercado, mas também os potenciais utilizadores e uma multiplicidade de intermediários dessas relações.

Neste caso, a negociação sobre o regime de justificação dos usos conduziu à mobilização de uma nova ordem de grandeza - a ordem da inspiração. Tendo sido introduzida na coordenação das actividades de uso dos fonógrafos, esta ordem teve impactos sobre a produção e comercialização dos artefactos, obrigando a ajustamentos no domínio das actividades industriais e mercantis dos mesmos. A articulação deste conjunto particular de actividades envolveu, num mesmo campo de acção, actores sociais e objectos tão diversos quanto os regimes de justificação mobilizados para a sua coordenação e conduziu à constituição de um campo específico de actividades o campo da indústria fonográfica. O seu desenvolvimento histórico foi incorporando sucessivamente actores e objectos que inicialmente estavam fora desse universo e, com eles, novas ordens de grandeza. Entre os primeiros terão estado os compositores e os autores, envolvidos neste campo através das suas composições e dos seus poemas, indispensáveis na produ-

\footnotetext{
${ }^{5}$ Michael Chanan dá conta de vários processos judiciais que foram accionados ainda antes da rectificação da Convenção de Berna, em 1908, e que tiverem diferentes desfechos. Em Inglaterra, em 1899, os editores de música em papel perderam as suas causas. Mas em França, em 1905, os tribunais decidiram contra a reprodução não autorizada de canções e de música e, em 1906, em Itália, a Sociedade Italiana de Autores e Compositores conseguiu conquistar, através da via judicial, o direito de royalties sobre as vendas de discos (Chanan, 1995).
} 
ção das gravações musicais. A sua entrada na arena implicou a disputa de novos modos de acção, desta vez orientados segundo a ordem cívica, de maneira a proteger os direitos de propriedade reconhecidos aos criadores e, com eles, as actividades artísticas.

\section{As ambiguidades contemporâneas e a dissolução de convenções}

Dos primórdios até aos nossos dias, muitos outros focos de ambiguidade e de incerteza foram surgindo: $i$ ) desde o padrão de relação com os consumidores de discos, mediado desde a década de vinte por novos objectos e novas actividades - os aparelhos de rádio e as emissões radiofónicas - e, a partir da década de cinquenta, pelos televisores e pela radiotelevisão; ii) aos estilos musicais das produções e registos fonográficos, substancialmente ampliados e reinventados a partir dos anos cinquenta e do lançamento do rock n'roll; iii) aos formatos das obras fonográficas que, após o lançamento dos discos de longa-duração (long-play), vêm a assumir a estrutura de álbuns, com uma narrativa articulada entre temas musicais; iv) à natureza das técnicas e tecnologias de gravação, tornadas acessíveis e manipuláveis, primeiro pelos músicos e intérpretes e, depois, também pelos consumidores; $v$ ) aos direitos de propriedade associados às obras musicais gravadas - já não só direitos de autores, mas também direitos conexos a esses, reivindicados e atribuídos a intérpretes e a produtores; etc., etc., etc. Em momentos sucessivos, tais incertezas deram origem a fortes disputas entre os actores presentes no campo, à reinvenção dos acordos existentes ou à negociação de outros novos acordos, agregadores de outras ordens de grandeza, de modo a garantir a sobrevivência das suas actividades comuns.

Desde os anos oitenta, contudo, o ritmo da introdução de incertezas tem vindo a acelerar. O desenvolvimento das tecnologias digitais, a sua importação para o universo da música gravada e a subsequente integração dos sistemas digitais, da informática e das tecnologias da comunicação vieram a ter consequências radicais, de efeito multiplicador, sobre todo o universo fonográfico. Num curto espaço de tempo, alteraram-se as condições da criação musical, da sua produção fonográfica, da sua difusão e do seu consumo.

Nos primeiros anos da década de oitenta, o desenvolvimento dos sintetizadores digitais e do primeiro interface digital para instrumentos (o MIDI) e o surgimento dos novos suportes de gravação em linguagem digital (os discos compactos) marcaram radicalmente a vida da indústria fonográfica e contribuíram para a redefinição dos valores de uso e das modalidades de consumo musical. 
Os sintetizadores surgiram em meados da década de setenta, quando a indústria de instrumentos musicais encetou a comercialização de instrumentos dotados de dispositivos de memória capazes de armazenar programas de som. O desenvolvimento das tecnologias digitais veio ampliar as potencialidades destes dispositivos e introduzir novas variantes de operadores de sons sintetizados, como a dos conhecidos samplers.

O desenvolvimento e a comercialização dos samplers digitais, seja como peças de hardware autónomas, seja como modalidades de software para computadores, converteu as técnicas digitais em operações acessíveis aos músicos. E na medida em que os samplers trabalham sobre qualquer tipo de som pré-gravado, a sua utilização introduziu novas práticas de produção e criação musical - as práticas de sampling. Estas constituem uma forma de citação musical através da qual os compositores procedem à incorporação de qualquer som pré-gravado num novo trabalho de gravação (Katz, 2004: 139).

A popularização do recurso aos sons digitalizados na produção musical revelou a conveniência da articulação entre os diferentes padrões de sintetizadores, conduzindo a um esforço de estandardização dos sinais digitais através da concepção de um interface para instrumentos digitais - o Musical Instrument Digital Interface (MIDI). O desenvolvimento deste dispositivo informático teve início em 1981, através de um conjunto de contactos informais entre representantes dos maiores fabricantes de equipamentos digitais de som, e a primeira versão desse interface -MIDI Specification 1.0 - surgiu nos mercados no Verão de 1983.

O MIDI tornou possível a conexão entre uma pletora de equipamentos, dos sintetizadores aos instrumentos musicais clássicos, através da linguagem digital. Para além de fornecer uma plataforma de comunicação entre diferentes dispositivos de produção musical, o sistema MIDI facultou o desenvolvimento de novas formas de composição, mistura e edição musical, nas quais o computador desempenha um papel central.

Já nos anos noventa, começaram a surgir nos mercados dirigidos aos consumidores não profissionais os primeiros gravadores digitais de múltiplas pistas, equipados com dispositivos de mistura e edição musical. Mas a produção de masters, ou matrizes, para edição comercial dependia ainda dos profissionais dos estúdios e da sua mestria. Todavia, o aperfeiçoamento dos sistemas informáticos, do hardware e do software, permitiu que os computadores pessoais pudessem funcionar como terminais digitais de áudio (digital audio workstations, DAW). Estas aplicações informáticas transformaram os computadores em versáteis gravadores digitais (Millard, 2005: 382), preparados para funcionar em articulação com outros dispositivos graças à popularização do sistema MIDI. 
A difusão das $D A W$, aliada à popularidade do sistema MIDI, aos sintetizadores digitais e aos samplers, teve significativos impactos sobre as formas de organização da produção musical. Em meados dos anos noventa, era possível montar, com custos relativamente baixos, estúdios domésticos com disponibilidades técnicas e tecnológicas semelhantes às encontradas nos estúdios profissionais.

Essas mudanças produziram impactos significativos sobre os estúdios e os seus profissionais, que perderam a importância que haviam conquistado no universo da música popular, a partir das décadas de setenta e oitenta. Nessa altura, a introdução dos gravadores de múltiplas pistas e o desenvolvimento das técnicas de mistura e de edição tinham-lhes proporcionado um lugar autónomo e central na produção musical, em detrimento dos próprios músicos (Théberge, 1997: 217). Desde então, os estúdios assumiam o estatuto de dispositivos colectivos de composição e produção musical, sob a coordenação dos produtores musicais cuja autoridade se fundava na mediação por eles desenvolvida entre músicos, técnicos, dispositivos, editoras e públicos (Hennion, 1989).

As tecnologias digitais possibilitaram aos músicos a instalação de estúdios domésticos dedicados às suas actividades de criação, de experimentação e de composição musical. E através deles os músicos reconquistaram o seu lugar como criadores, fugindo ao controlo exercido por produtores e engenheiros de som. Os estúdios profissionais não desapareceram, mas perderam proeminência como dispositivos colectivos de criação, assumindo frequentemente um papel complementar na produção final dos temas musicais.

Do ponto de vista cultural, as mudanças tecnológicas tiveram também impactos significativos sobre a criação musical, multiplicando as possibilidades de algumas das tendências criativas já anunciadas na década de setenta e intensamente exploradas nas duas décadas seguintes. Entre essas tendências encontrava-se o Rap, uma expressão musical com origens no Hip Hop, uma subcultura afro-americana de rua, nascida no South Bronx, em Nova Iorque, nos anos setenta, envolvendo a música, a dança e o graffiti.

As principais características do Rap - a combinação de uma narrativa vocal, expressa de forma compassada sobre um fundo musical rítmico electrónico, em que a cadência da voz e da batida musical operam em conjunto $^{6}$ - estão directamente relacionadas com as suas raízes culturais e com a sua associação a uma forma musical dançada (Rose, 1994: 1-20). A batida da música Rap é conseguida através do recurso a uma técnica explorada

${ }^{6}$ A própria sigla faz eco dessa forma particular de combinar uma batida e a voz ritmada: $R A P$, Rythm and Poetry (Fradique, 2003: 39). 
pelos $D J s$, em meados dos anos setenta, nos clubes e nas discotecas de Nova Iorque, Chicago e Washington:

A batida da música rap é produzida por um processo conhecido como 'scratchmixing' através do qual um gira-discos de dois pratos, originalmente concebido para proporcionar uma sequência contínua de faixas de dança em discotecas e clubes nocturnos, é transformado ele próprio num instrumento musical. Usando um dos pratos para produzir o ritmo, conseguido através do manejo de um disco de modo a que uma determinada sequência de compassos é continuamente repetida, o DJ usa então o segundo prato para misturar nesse ritmo fragmentos de sons e temas instrumentais de outros discos. (Bennett, 1999: 78-79)

Através destas técnicas, e com recurso a fragmentos de músicas pré-gravadas, produz-se um dos elementos cruciais deste estilo musical, aquilo que Teresa Fradique designa como um novo tipo de percussão (Fradique, 2003:39).

Envolvendo um modo de criação que inicialmente dependia de processos mecânicos de colagem e de recomposição de sons, os rappers encontraram nas tecnologias digitais múltiplos recursos para a criação dos seus ritmos musicais. E não só os rappers. Também os DJs exploraram esses equipamentos para compor outras expressões musicais, como a House ou a Techno.

De facto, se, em Nova Iorque, as técnicas desenvolvidas pelos DJs foram apropriadas pela subcultura de rua Hip Hop, dando origem ao Rap, em Chicago, elas foram evoluindo no contexto dos próprios clubes de dança, dando lugar à House music, cujo nome advém de um dos clubes mais populares na cidade - o Warehouse Club (Langlois, 1992). No centro da cena musical House encontra-se o DJ, um profissional cujo papel evoluiu ao longo das décadas de setenta e oitenta, deixando de ser apenas o responsável pela selecção e substituição dos discos ao longo de uma noite, para se transformar numa espécie de músico (Langlois, 1992: 230). No final dos anos setenta, os DJs usavam uma técnica particular para a manipulação dos discos - a blend mixing, como era conhecida - através da qual fragmentos de músicas impressas em discos de vinil eram misturados com recurso a um leitor de discos com dois pratos, de modo a produzir novos sons e texturas musicais e mesmo novas peças musicais. O estilo dos $D J s$ norte-americanos rapidamente se popularizou entre os $D J s$ da Europa e do resto do mundo, que exploraram as suas próprias técnicas de mistura. Desta forma, a House passou a influenciar a música de dança dos anos oitenta e noventa.

Outra das influências dessa mesma música de dança terá sido a Techno, uma forma de música electrónica, construída a partir do uso de computadores, que surgiu em Düsseldorf, na Alemanha, pelas mãos de um grupo 
designado Kraftwerk. A música dos Kraftwerk tornou-se popular entre os $D J s$ de Chicago e outras cidades norte-americanas, que passaram a integrar os sons dessa música electrónica nas suas misturas. As tecnologias digitais, introduzidas na década de oitenta, influenciaram tanto estas novas expressões musicais como as experiências dos pioneiros daquilo que Andy Bennett designa como electro-pop (Bennett, 2001: 118-135).

Os computadores, os samplers, o sistema MIDI permitiram aos DJs desenvolver novas técnicas de animação musical dos clubes de dança, sobrepondo a música dos discos a suportes sonoros pré-produzidos e registados digitalmente e articulando todos os sons de forma inovadora:

Na medida em que a música House tem sido frequentemente construída a partir de pedaços de materiais sonoros pré-gravados digitalmente (sampled), a 'arte' da composição musical no seu sentido mais comum é virtualmente inexistente, e o género é, portanto, relativamente acessível a compositores com o tipo de formação dos disc-jockeys. Com um sampler, sintetizadores e um computador ligados por um sistema MIDI, pode-se perfeitamente sincronizar uma multiplicidade de 'vozes' numa batida e programá-las para entrar numa peça quando se pretender. [...] Operar com um código digital em vez de uma fita electromagnética permite uma edição fácil e muito rápida do material, que pode ser revertido, retardado ou acelerado consoante for mais apropriado. (Langlois, 1992: 231)

Mas, se o Rap e as novas músicas de dança, a House, a Techno, são ilustrações flagrantes do modo como as novas tecnologias digitais foram rapidamente absorvidas na produção musical, participando da recriação de estilos e práticas musicais, elas não estão isoladas do que se passa no restante panorama da música popular gravada. De facto, ao longo das décadas de oitenta e de noventa, o recurso às tecnologias digitais tornaram a mistura, o sampling e os sons sinteticamente processados em técnicas de composição musical transversais a todos os géneros musicais.

A produção musical passou a recorrer, com frequência, à reciclagem de temas musicais populares em outras épocas e à sua apropriação como matéria-prima para a criação de novas expressões musicais. ${ }^{7}$ Esses processos

\footnotetext{
7 "Usando técnicas de sampling, músicos e produtores podem efectivamente 'retirar' sons dos seus contextos 'originais' e transformá-los em novas peças de música. Pode-se ouvir os primeiros exemplos de sampling na construção de 'nova música' no trabalho do agrupamento JAMs, de meados da década de 1980, que mais tarde reapareceu como KLF. Os JAMs criaram temas como 'The Queen and I', que misturava pedaços dos ABBA e dos Sex Pistols com o Hino Nacional Britânico, e 'Whitney Joins JAMs', que apresentava samples de 'I Wanna Dance with Somebody (Who Loves Me)', de Whithney Houston, 'Theme from Shaft', de Isaac Hayes, e o tema musical da série de culto norte-americana Missão Impossível, dos anos 1970 (Beadle, 1993: 111-112)” (Bennett, 2001: 121).
} 
foram explorados com o apoio dos múltiplos recursos de manipulação tecnológica dos sons acústicos, humanos e não humanos, e de integração de sons puramente sintetizados na composição musical. E se, do ponto de vista estritamente musical, estas formas de composição levantaram diversas contendas, na perspectiva da produção fonográfica, elas acarretaram novos problemas relativos à identificação de autorias e à atribuição do copyright.

Para além das repercussões sobre a produção musical, a aplicação das tecnologias digitais aos suportes de gravação e aos equipamentos de reprodução musical aconteceu no início da década de oitenta, abrindo caminho a transformações radicais no universo dos consumos da música gravada.

A Sony e a Philips foram as duas companhias responsáveis por essa aplicação. A cooperação entre as duas companhias permitiu o desenvolvimento dos primeiros equipamentos digitais e dos respectivos discos - os compact discs (CDs). O protótipo do sistema foi apresentado pela Philips à indústria fonográfica em 1981, mas só em 1982 os primeiros discos compactos foram postos à venda no Japão e nos Estados Unidos e, em 1983, foram introduzidos nos mercados europeus (Gronow e Saunio, 1999: 147-212). A Philips e a Sony desenvolveram, então, uma agressiva promoção junto da indústria fonográfica, de modo a conseguir ultrapassar a concorrência e impor o seu sistema de discos compactos como sistema padrão. Uma das grandes vantagens da parceria entre estas companhias residiu no facto de elas poderem explorar de forma imediata a combinação entre o novo hardware e o software aplicável, isto é, a música gravada. O facto de a Philips ser a companhia mãe da Polygram possibilitou essa ligação directa, entre a introdução da nova tecnologia e o mercado da música gravada, revelando-se fundamental para a ilustração das potencialidades dos novos equipamentos e dos novos suportes.

As principais vantagens das novas tecnologias digitais residiam na limpidez do registo sonoro e da sua reprodução, no acréscimo do tempo de gravação disponível dos novos discos, nas possibilidades abertas para uma leitura aleatória dos discos e, sobretudo, a sua menor susceptibilidade aos efeitos do uso (Millard, 2005: 346-356). As suas principais desvantagens decorriam das dificuldades inerentes à assimilação de novas tecnologias e da sua adaptação por parte dos agentes nos campos fonográficos e nos mercados. De facto, a sua introdução impunha uma ruptura com as capacidades instaladas e a necessidade de uma renovação completa dos sistemas de leitura e de reprodução de som que equipavam os consumidores. Esse reequipamento acarretava custos relativamente elevados, num momento em que os sistemas de reprodução de cassetes, economicamente mais acessíveis, estavam ainda a conquistar públicos. 
Ainda assim, as novas tecnologias digitais revelaram-se imediatamente interessantes, sobretudo para a difusão da música clássica. Os amantes desta música, normalmente consumidores exigentes, apreciadores da qualidade técnica do som da música gravada, mostraram-se rapidamente interessados pelas novas tecnologias. Além disso, a maior capacidade dos discos compactos permitia pela primeira vez uma audição ininterrupta de obras mais longas, como as sinfonias ou os grandes concertos.

Não obstante o seu bom acolhimento no universo da música erudita, só na segunda metade da década de oitenta a venda de CDs se tornou mais popular e o seu mercado se tornou apetecível para as editoras. De facto, durante a primeira metade da década, embora o mercado dos discos de vinil tivesse sofrido uma crise profunda, o mercado das cassetes áudio encontrava-se em forte expansão. Foi preciso tempo para que as companhias percebessem as vantagens das novas tecnologias, e os consumidores as reconhecessem, ultrapassando as incertezas associadas à introdução de um novo sistema de gravação e reprodução de sons.

Ultrapassadas essas hesitações, os CDs revelaram-se uma oportunidade de excelência para as companhias fonográficas. Permitiram o relançamento no mercado de muitos registos disponíveis nos seus fundos de catálogo, através da sua transposição para som digital e da sua edição em disco compacto. Ajudaram a conquistar novas gerações de consumidores, agora dispostas a constituírem os seus arquivos musicais pessoais, enquanto atraíam consumidores já fidelizados para a renovação das suas colecções nos novos formatos. Para além de que ofereceram uma oportunidade para proceder de forma justificável a uma subida de preços dos CDs. É essa renovação de discos, de gravações e de preços que explica, em grande medida, o crescimento dos mercados fonográficos na segunda metade da década de oitenta, no fim da qual a venda de discos de vinil nos principais mercados fonográficos tinha sido claramente ultrapassada pela venda de CDs (Gronow e Saunio, 1999: 147-212). ${ }^{8}$

Menos de dez anos após a introdução dos primeiros discos compactos e dos respectivos equipamentos de leitura, começaram a surgir nos mercados os primeiros sistemas de gravação áudio digital: o Digital Audio System (DAT) da Sony, a Digital Compact Cassette (DCC) da Philips e o Mini Disc $(M D)$, também da Sony. Nenhum destes suportes e formatos teve sucesso nos mercados. Desta vez, a incapacidade da Sony e da Philips em chegarem

\footnotetext{
${ }^{8}$ Isto acontece, de facto, nos mercados fonográficos da América do Norte, da Europa e do Japão. No entanto, como mostram os trabalhos de Peter Manuel (1993) e de Roger Wallis e Krister Mälm (1984), a subsistência dos mercados fonográficos periféricos depende das tecnologias mais económicas, principalmente das cassetes.
} 
a um entendimento sobre o padrão tecnológico a adoptar gerou uma incompatibilidade entre os sistemas e uma forte concorrência no mercado. A resistência das companhias fonográficas em editar nestes formatos terá contribuído, igualmente, para o fracasso destas tecnologias.

De um modo geral, a indústria fonográfica temia a comercialização aberta das novas tecnologias de gravação digital pelo facto de elas abrirem renovadas possibilidades para a reprodução não autorizada de fonogramas. A pirataria passara a ser uma preocupação central para os campos fonográficos desde a popularização dos sistemas de gravação magnética e, por isso, as associações representativas do sector nos mercados norte-americano (em particular, a Records Industry American Assotiation - RIAA) e europeu (representadas pela International Federation of Phonographic Industry - IFPI) mobilizaram as suas forças para evitar a difusão das tecnologias de gravação digital.

Não obstante a atitude conservadora da indústria, o desenvolvimento integrado dos sistemas informáticos e de entretenimento conduziu à introdução nos mercados de dispositivos informáticos capazes de operar com sistemas de codificação digital para vídeo, áudio, texto, animação e esquemas de interactivos. Os CD-Rom foram os primeiros suportes desta natureza a surgir, podendo ser lidos através de uma drive em qualquer computador pessoal. Seguiram-se os discos compactos graváveis (CD-R), os discos compactos regraváveis (CD-RW) e, mais tarde, os DVDs. Estes desenvolvimentos deixaram de ser controláveis pela indústria fonográfica e os mecanismos de gravação digital de fonogramas passaram a estar disponíveis nos mercados de equipamentos domésticos e acessíveis aos consumidores a preços relativamente baixos.

No final da década de noventa, as possibilidades oferecidas aos consumidores pelas novas tecnologias digitais - adquirir um CD de música gravada, copiá-lo para o disco rígido de um computador ou reproduzi-lo, copiando-o para outro CD - foram multiplicadas pelas inovações que ocorreram no universo das tecnologias da informação. Essas inovações seguem-se à constituição, em 1989, da rede mundial de comunicação entre computadores - a World Wide Web $(W W W)^{9}$ - e, em 1994, ao surgimento do primeiro browser comercial - o Netscape.

A segunda metade da década de noventa foi fértil em inovações técnicas e tecnológicas que exploravam as inúmeras potencialidades oferecidas pela World Wide Web e que, em poucos anos, transformaram radicalmente os

\footnotetext{
${ }_{9}^{9}$ O protocolo que estabeleceu a internet surgiu em 1974, mas só em 1989 foi estabelecida a World
} Wide Web, WWW (Kretschemer, Klimis e Wallis, 2001: 418). 
mecanismos de distribuição e acesso à música gravada, alterando a face dos mercados fonográficos. Ainda em 1993, Rob Lord e Jeff Patterson arquitectaram uma espécie de arquivo musical digital em formato MP2, ${ }^{10} \mathrm{o}$ Internet Underground Music Archive - IUMA, particularmente destinado à música alternativa e independente. As condições de operacionalidade da Internet e o desenvolvimento ainda incipiente dos sistemas de codificação de ficheiros áudio não permitiram, contudo, que este serviço se afirmasse como uma alternativa às clássicas formas de distribuição musical. Em 1995, Rob Glaser apresentou o Real Audio System, um dispositivo que comprimia os ficheiros áudio e os remetia para os utilizadores da internet. A ele associou o Real Player, o software que, quando instalado nos computadores pessoais (PCs), fazia a leitura dos ficheiros áudio e vídeo comprimidos através do Real Audio System. Em 1997, Justin Frankel ajudou a desenvolver o Winamp, um programa que lia ficheiros musicais codificados em MP3 e os reproduzia nos computadores domésticos.

Com o advento e a rápida difusão do MP3 abriram-se definitivamente as possibilidades de circulação da música gravada através da internet, surgindo, desde então, inúmeros portais disponibilizando conteúdos de som e de imagem. Um dos mais conhecidos terá sido o MP3.com, aberto por Michael Robertson em 1997. Inicialmente vocacionado para divulgar informações acerca dos cada vez mais comuns portais de música em formato MP3, transformou-se rapidamente num deles, alojando sobretudo os trabalhos de bandas independentes (Millard, 2005: 388-402). Em 1999, a Diamond Multimedia introduziu o primeiro leitor autónomo de MP3: o Rio PMP 300. Depois dele, muito outros modelos surgiram, de tal modo que, como sugere Andre Millard (2005: 395), os leitores de MP3 se transformaram nos Walkman do século XXI.

As companhias fonográficas mantiveram a distância relativamente a estes processos. Continuaram a apostar na produção de CDs e, sobretudo, na sua distribuição e comércio tradicionais, apesar de algumas terem iniciado a comercialização de CDs através da internet. ${ }^{11}$

No entanto, no final da década de noventa, quando começavam a ser adoptados novos mecanismos de distribuição física de informação digital

\footnotetext{
${ }^{10} \mathrm{O}$ MP2, tal como o MP3, é um sistema de codificação digital de sons. O MP3 foi desenvolvido, desde 1985, pelo Fraunhofer Institute for Integrated Circuites, na Alemanha, e introduzido em 1992. A sua adopção como parte dos sistemas padrão de compressão digital de áudio e vídeo foi definida pelo Motion Pictures Experts Group (MPEG) Layer3 em 1994 (Kretschemer, Klimis e Wallis, 2001: 419). ${ }_{11}$ Muitas delas adoptaram o Real Audio System para colocar online pequenas amostras dos temas contidos nos seus discos, audíveis pelos internautas que possuíssem o Real Player. No entanto, não disponibilizavam a totalidade das faixas contidas nos CDs. O conjunto global dos temas mantinha-se apenas associado aos discos enquanto objectos físicos.
} 
- a banda larga, o cabo óptico, os modems de alta velocidade -, proporcionando maior rapidez e maior qualidade ao fluxo de informação na internet, surgiram os dispositivos de troca directa de música gravada através da rede, os sistemas peer-to-peer (P2P). Shawn Fanning tornou-se um nome familiar para os utilizadores da internet pelo facto de ter desenvolvido este processo através do sistema Napster, introduzido na rede em 1999 e desenhado para proporcionar uma troca livre e directa entre amantes da música.

Os sistemas P2P revolucionaram o acesso à música gravada, facilitando a constituição de audiências globais, interligada pela World Wide Web e capazes de partilhar, sem outros intermediários para além dos dispositivos técnicos e tecnológicos, ficheiros de áudio. Se as outras tecnologias digitais já ofereciam aos consumidores a possibilidade de controlo e manipulação sobre os registos musicais, os programas de troca directa de conteúdos musicais abriram-lhes oportunidades infinitas de acesso às audiotecas privadas de outros utilizadores da rede. De facto, as redes P2P são radicalmente diferentes do tradicional "modelo cliente-servidor, no qual a informação flui entre uma fonte centralizada (o servidor, um computador ou conjunto de computadores que armazenam e distribuem os dados) e os seus utilizadores (os clientes, que solicitam dados ao servidor). Em vez disso, o modelo P2P descreve uma rede descentralizada, na qual cada computador tem acesso directo a determinados ficheiros armazenados em cada um dos outros computadores; a circulação de dados entre os membros de uma rede é conhecida como partilha de ficheiros" (Katz, 2004:161).

Neste contexto, a posição das companhias fonográficas achou-se seriamente ameaçada. Por um lado, os novos meios e sistemas de comunicação em rede constituíam uma ameaça às suas funções de selecção e difusão de obras musicais e às suas estruturas de distribuição e comercialização de fonogramas. Por outro lado, os sistemas P2P pulverizaram os princípios basilares da propriedade intelectual, oferecendo possibilidades inimagináveis de uso ilegal dos fonogramas e ameaçando o controlo dos direitos de propriedade intelectual distribuídos pelos vários agentes da cadeia de valor do sector fonográfico. À ameaça da pirataria industrial fortalecida pelas tecnologias digitais, somava-se agora a explosão das possibilidades de cópia ilegal pelos consumidores.

Abriu-se assim um conjunto de possibilidades que alteraram radicalmente os modos de relação dos consumidores musicais com o universo da música gravada e, com ela, as convenções que regeram durante longo tempo a definição dos valores de uso desta música. Em última análise, estas alterações geraram desentendimentos sobre a definição dos próprios objectos da indústria fonográfica, reflectindo equívocos que haviam já preenchido os 
primórdios desta indústria. De facto, a indústria fonográfica foi incapaz de perceber e assimilar o processo de desmaterialização da música gravada, não acompanhando a reinvenção dos dispositivos de mediação da criação e do consumo. Esses dispositivos permitiram uma recriação significativa da cultura musical, dos processos de constituição de critérios de fruição lúdica e estética da música e das práticas de uso e manipulação dessa mesma música. Simultaneamente, os mesmos dispositivos alteraram as condições de criação, de registo e de difusão musical, possibilitando, em última análise, uma relação directa e recíproca entre criadores e consumidores.

Através da rede, os consumidores revelam-se cada vez mais como amantes de música, no sentido em que Antoine Hennion nos fala (Hennion, 2001). Seleccionam temas musicais, elegem intérpretes, partilham preferências, justificam os seus gostos e argumentam em defesa dos seus critérios, contrapõem escolhas, comparam temas e intérpretes, comunicam com os criadores, compõem eles próprios selecções musicais que estabelecem diálogos inéditos entre temas e intérpretes... Isto, para além de poderem articular todas essas actividades com o universo das práticas criativas, hoje acessíveis através da articulação entre os dispositivos informáticos, os equipamentos de produção e de registo de som e os instrumentos musicais.

A rede revelou-se como um dispositivo técnico que ampliou e transformou brutalmente as redes de socialização cultural, as práticas de construção do gosto musical e os modos de relação com as obras musicais (Hennion, 2005). Nesse sentido, os sistemas digitais, a rede e, em particular, os dispositivos $\mathrm{P} 2 \mathrm{P}$ abriram um conjunto de novas possibilidades para a actualização do princípio da grandeza da inspiração na definição do valor dos fonogramas.

De um modo geral, as mudanças que têm vindo a ocorrer desde a década de 1980 - mudanças em diversos dispositivos tecnológicos, nos processos de composição, formas e conteúdos musicais, nos dispositivos do mercado, nas modalidades de uso dos consumidores - vieram alterar de uma forma radical uma parte significativa das convenções de funcionamento do campo fonográfico, nas quais se plasmavam as ordens de grandeza que presidiam ao seu funcionamento. Os novos dispositivos tecnológicos introduziram incertezas agudas relativamente àqueles que, ao longo da sua história, se foram definindo como os objectos específicos da actividade fonográfica - os fonogramas. Poderão eles continuar a ser discos? Ou estarão estes objectos condenados a desaparecer e a dar definitivamente lugar a protocolos imateriais? As novas modalidades de composição e criação musical alteraram a convenção sobre as obras musicais e a sua originalidade. E com isso introduziram muitas novas questões relativamente à definição dos direitos 
de autor, consagrados desde o início do século Xx, e aos mecanismos de funcionamento da ordem cívica que presidiu à coordenação da actividade fonográfica neste domínio. A transformação dos dispositivos de mercado, nomeadamente o surgimento de sistemas de troca directa, não comercial e não material, ameaçou os mecanismos do comércio a retalho convencional e obrigou à invenção de dispositivos de comércio online. Nestes novos dispositivos, os protocolos de cálculo associados são radicalmente diferentes dos mobilizados no comércio clássico, ${ }^{12}$ impondo mudanças na produção do valor de mercado dos fonogramas. Ainda assim, a troca directa e não monetária entre consumidores continua a gerar incertezas nesse domínio. As mudanças do uso que os consumidores fazem dos fonogramas, que ultrapassa a audição de discos, para incluir amplamente a sua reprodução e partilha, mas também a sua recriação, alteraram as convenções da cultura musical subjacentes ao consumo fonográfico e geraram fortes controvérsias sobre as regras do mercado, sobre as convenções da propriedade musical e sobre a própria convenção acerca da distinção entre criador, obra e consumidor, uma convenção que é um dos fundamentos da instituição dos campos culturais modernos.

\section{Conclusão}

Para terminar, retomo muito brevemente a ideia inicial deste ensaio, na qual expressava perplexidade face à ligeireza com que frequentemente as indústrias culturais são tratadas pela literatura sociológica. O que a história da indústria fonográfica nos mostra a esse propósito é que as indústrias culturais constituem campos organizacionais com um elevado grau de complexidade. Neles operam não apenas as lógicas da acção técnico-industrial e mercantil, classicamente associadas ao universo das actividades económicas, mas também as que dominam nas esferas culturais e artísticas - a lógica da inspiração e a da reputação - e a que orienta a regulação pública - a lógica cívica. A complexidade do campo das indústrias culturais decorre da coexistência dessa diversidade de lógicas e regimes de coordenação que, sendo incomensuráveis entre si, coexistem na organização e na dinâmica do campo. Uma coexistência suportada, fundamentalmente, pelo recurso a numerosas convenções instituídas que permitem a operacionalização desses regimes e a sua alternância no decurso das actividades.

Os momentos em que surgem e se formam novos universos de actividades, como aconteceu nas duas últimas décadas do século XIX e nas primeiras do século XX, ao longo das quais se foram afirmando e aperfeiçoando as

\footnotetext{
${ }^{12}$ Sobre a concepção dos mercados como dispositivos colectivos de cálculo, ver Callon e Muniesa, 2005.
} 
actividades fonográficas, permitem-nos dar conta da diversidade de princípios convocados por esses campos de acção. Mas essa percepção torna-se particularmente aguda em momentos de crise, como aquela que a indústria fonográfica tem vivido nas duas últimas décadas em resultado da redefinição de várias convenções, seja de carácter técnico-industrial, seja de natureza cultural, mercantil ou mesmo cívica. A transformação dessas convenções teve múltiplas consequências sobre a coordenação das actividades e sobre a estrutura do campo, instalando um ambiente de dúvidas e de incertezas quanto à legitimidade dos regimes de justificação instituídos. Essas incertezas revelaram-se particularmente agudas porque pulverizaram as disputas não só em torno dos objectos e dos dispositivos materiais pertinentes para o universo fonográfico, mas também da definição dos actores relevantes, dos testes que permitem avaliar as respectivas grandezas e definir as suas hierarquias e, sobretudo, em torno dos próprios princípios de grandeza subjacentes às diversas actividades. Uma multiplicidade de possíveis focos de incerteza que mostram à saciedade a irredutibilidade dos campos das indústrias culturais à clássica dicotomia entre economia e cultura e ilustram uma densidade de processos ainda muito pouco estudados.

\section{Referências bibliográficas}

Bennett, Andy (1999), "Hip hop am Main: The localization of rap music and hip hop culture", Media, Culture \& Society, 21(1), 77-91.

Bennett, Andy (2001), "Contemporary Dance Music and Club Culture", in Andy Bennett, Cultures of Popular Music. Buckingham/Philadelphia: Open University Press, 118-135.

Boltanski, Luc; Thévenot, Laurent (1991), De la justification. Les économies de la grandeur. Paris: Éditions Gallimard.

Boltanski, Luc; Thévenot, Laurent (1999), "The Sociology of Critical Capacity”, European Journal of Social Theory, 2(3), 259-377.

Bourdieu, Pierre (1996), As regras da arte. Génese e estrutura do campo literário. Lisboa: Editorial Presença [1992].

Callon, Michel; Muniesa, Fabian (2005), "Economic Markets as Calculative Collective Devices”, Organization Studies, 26(8), 1229-1250.

Chanan, Michael (1995), Repeated Takes. A Short History of Recording and Its Effects on Music. London/New York: Verso.

DeNora, Tia (1995), "Beethoven et l'invention du génie", Actes de la recherché en sciences sociales, $110,36-45$.

Fligstein, Neil (1996), "Markets as Politics: A Political-Cultural Approach to Market Institutions”, American Sociological Review, 61(4), 656-73. 
Fligstein, Neil (2001), The Architecture of Markets. An Economic Sociology of Twenty-First-Century Capitalist Societies. Princeton/Oxford: Princeton University Press. Fradique, Teresa (2003), Fixar o movimento: representações da música rap em Portugal. Lisboa: D. Quixote.

Frith, Simon (1988), "The Industrialization of Music”, in Simon Frith, Music for Pleasure. Essays in the Sociology of Pop. Cambridge: Polity Press.

Gronow, Pekka; Saunio, Ilpo (1999), An International History of the Recording Industry. London/New York: Cassell.

Hennion, Antoine (1989), "An Intermediary between Production and Consumption: The Producer of Popular Music”, Science, Technology \& Human Values, 14(4), 400-424.

Hennion, Antoine (2001), "Music Lovers. Taste as Performance”, Theory, Culture $\mathcal{E}$ Society, 18(5), 1-22.

Hennion, Antoine (2005), "Pragmatics of Taste", in Mark D. Jacobs and Nancy Weiss Hanrahan (orgs.), The Blackwell Companion to the Sociology of Culture. Malden/Oxford/Carlton: Blackwell Publishing, 131-144.

Katz, Mark (2004), Capturing Sound. How Technology Has Changed Music. Berkeley/Los Angeles/London: University of California Press.

Kretschmer, Martin; Klimis, George Michael; Wallis, Roger (2001), "Music in Electronic Markets. An empirical study”, New Media E Society, 3(4), 417-441.

Langlois, Tony (1992), "Can you feel it? DJs and House Music Culture in the UK", Popular Music, 11(2), 229-238.

Maisonneuve, Sophie (2001a), "De 'la machine parlante' à l'auditeur. Le disque et la naissance d'une nouvelle culture musicale dans les années 1920-1930", Terrain, 37 - Músique et émotion. URL: http://terrain.revues.org/document1289.html. Colocado em linha a 6 de Março de 2007 e consultado a 12 de Julho de 2007.

Maisonneuve, Sophie (2001b), "Between history and commodity: The production of a musical patrimony through the record in the 1920-1930s", Poetics, 29, 89-108.

Maisonneuve, Sophie (2002), Le disque et la musique classique en Europe, 1877-1949: l'invention d'un médium musical, entre mutations de l'écoute et formation d'un patrimoine. Tese de Doutoramento apresentada no Instituto Universitário Europeu. Florence: IUE (policopiado).

Manuel, Peter (1993), Cassette Culture. Popular Music and Technology in North India. Chicago/London: The University of Chicago Press.

Millard, Andre (2005), America on Record. History of Recorded Sound. New York: Cambridge University Press.

Morton, David (2000), "High Culture, High Fidelity and the Making of Recordings in the American Record Industry”, in David Morton, Off Record. The Technology and Culture of Sound Recording in America. New Brunswick/New Jersey/London: Rutgers University Press. 
Powell, Walter; DiMaggio, Paul (1991), “The Iron Cage Revisited. Institutional Isomorphism and Collective Rationality in Organizational Fields", in Walter W. Powell e Paul DiMaggio (orgs.), The New Institutionalism in Organizational Analysis. Chicago: University of Chicago Press, 1-38.

Read, Oliver; Welch, Walter L. (1976), From Tin Foil to Stereo. Evolution of the Phonograph. Indianapolis/Kansas City/New York: Howard W. Sams \& Co., Inc; The Bobbs-Merril Co., Inc.

Rose, Tricia (1994), Black Noise. Rap Music and Black Culture in Contemporary America. Hannover/London: Wesleyen University Press.

Théberge, Paul (1997), Any Sound You Can Imagine. Making Music, Consuming Technology. Hanover/London: Wesleyan University Press.

Thévenot, Laurent (2001), "Organized Complexity. Conventions of Coordination and the Composition of Economic Arrangements", European Journal of Social Theory, 4(4), 405-425.

Thévenot, Laurent (2002), "Conventions of Co-ordination and the Framing of Uncertainty”, in Edward Fullbrook (org.), Intersubjectivity in Economics. Agents and Structures. London/New York: Routledge, 181-197.

Wallis, Roger; Mälm, Krister (1984), Big Sounds from Small Peoples. The Music Industry in Small Countries. London: Constable.

Weber, William (1989), "Mentalité et origines du canon musical en France et en Angleterre au XVIIIe siècle”, Annales ESC, 4, 849-873. 